\title{
Disparate genetic influences on polycystic ovary syndrome (PCOS) and type 2 diabetes revealed by a lack of association between common variants within the $T C F 7 L 2$ gene and PCOS
}

T. M. Barber • A. J. Bennett • C. J. Groves • U. Sovio •

A. Ruokonen - H. Martikainen • A. Pouta •

A.-L. Hartikainen • P. Elliott • J. A. H. Wass •

M.-R. Järvelin • E. Zeggini • S. Franks • M. I. McCarthy

Received: 27 June 2007 / Accepted: 23 July 2007 / Published online: 6 September 2007

(C) Springer-Verlag 2007

\begin{abstract}
Aims/hypothesis Common variants of the gene encoding transcription factor 7-like 2 (TCF7L2) have a powerful effect on individual risk of type 2 diabetes (per allele odds ratio 1.35). Polycystic ovary syndrome (PCOS) and type 2 diabetes are familial conditions sharing common features. Based on this, the aim of the present study was to establish whether variation in $T C F 7 L 2$ also influences the development of PCOS.

Methods We conducted a genetic association study of variants of TCF7L2 (rs7903146 and rs12255372) using both case-control and quantitative trait approaches. Case-control analyses were conducted in (1) 369 PCOS cases and 2574
\end{abstract}

T. M. Barber $(\bowtie) \cdot$ A. J. Bennett • C. J. Groves · J. A. H. Wass •

M. I. McCarthy

Oxford Centre for Diabetes, Endocrinology and Metabolism,

Churchill Hospital,

Old Road, Headington,

Oxford OX3 7LJ, UK

e-mail: tom.barber@drl.ox.ac.uk

E. Zeggini $\cdot$ M. I. McCarthy

Wellcome Trust Centre for Human Genetics,

Oxford, UK

S. Franks

Institute of Reproductive and Developmental Biology,

Imperial College (Hammersmith Campus),

London, UK

U. Sovio · P. Elliott • M.-R. Järvelin

Department of Epidemiology and Public Health,

Imperial College (St Mary's Campus),

London, UK controls of UK British/Irish origin, and (2) 540 women with PCOS symptoms and 1083 controls from the Northern Finland Birth Cohort of 1966. Quantitative trait analyses (androgen levels) were also performed (1249 individuals).

Results There was no association between rs7903146 and PCOS in the UK case-control study (Cochran-Armitage test, $p=0.51$ ); nor with symptomatic status in the Finnish cohort $(p=0.36)$. In addition, there were no relationships between the TCF7L2 single nucleotide polymorphism rs7903146 and androgen levels (UK cases, $p=0.99$; Finnish controls, $p=0.57$; Finnish symptomatic cases, $p=0.80$ ). Results at rs 12255372 were similar, reflecting strong linkage disequilibrium with rs7903146.

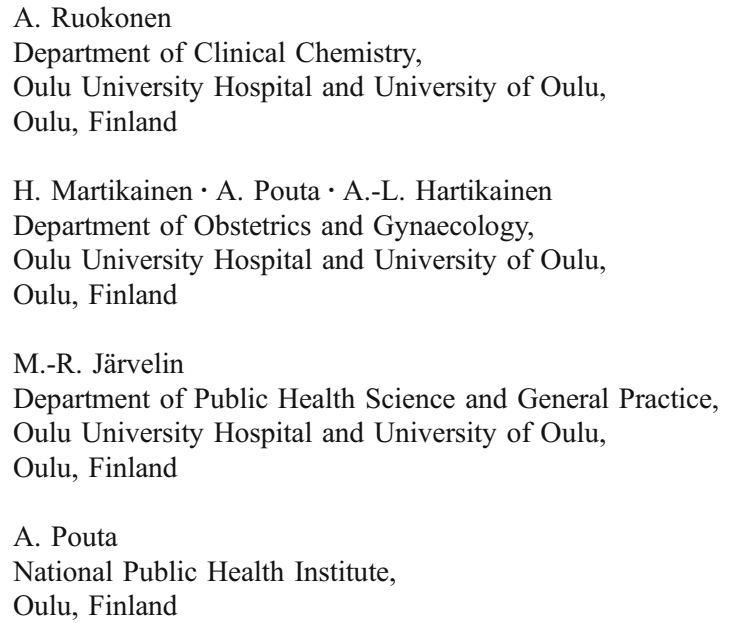


Conclusions/interpretation Our study was powered to detect an effect on PCOS susceptibility similar to that previously reported for these variants on type 2 diabetes. Failure to detect any evident association with PCOS provides the strongest evidence yet that the genetic architecture of these related conditions is qualitatively distinct.

Keywords Polycystic ovary syndrome - TCF $7 L 2$ variants . Type 2 diabetes mellitus

$\begin{array}{ll}\text { Abbreviations } \\ \text { 58BC } & \text { 1958 British Birth Cohort } \\ \text { FAI } & \text { Free androgen index } \\ \text { HRC }+ & \text { Human Random Control } \\ \text { NFBC1966 } & \text { Northern Finland Birth Cohort of } 1966 \\ \text { OR } & \text { Odds ratio } \\ \text { PCOS } & \text { Polycystic ovary syndrome } \\ \text { SHBG } & \text { Sex hormone-binding globulin } \\ \text { SNP } & \text { Single nucleotide polymorphism } \\ \text { TCF7L2 } & \text { Transcription factor 7-like 2 }\end{array}$

\section{Introduction}

Polycystic ovary syndrome (PCOS) and type 2 diabetes mellitus share common features. These include pathophysiology (abdominal obesity, insulin resistance and disturbed beta cell function are characteristic of both conditions) and epidemiology (many women with PCOS also develop type 2 diabetes, and vice versa) [1]. Given compelling evidence for a substantial genetic contribution to susceptibility to both conditions [1], known type 2 diabetes susceptibility genes emerge as strong candidates for a role in the development of PCOS.

Common variants in the gene encoding transcription factor 7-like 2 (TCF7L2) have been reproducibly shown to display powerful associations with type 2 diabetes in a number of studies [2-4], with a typical per allele odds ratio (OR) of $\sim 1.35$. Most current evidence favours impaired insulin secretion as the mechanism responsible [3, 5]. Although insulin resistance clearly plays a major role in the aetiology of PCOS, there is evidence for a concomitant (potentially primary) disturbance of beta cell function [6], endorsing the biological candidacy of TCF $2 \mathrm{~L} 2$ with respect to susceptibility to PCOS.

The causal variant within TCF7L2 has yet to be definitively identified. However, two single nucleotide polymorphisms (SNPs; rs7903146 and rs12255372) within TCF7L2 display the strongest effects on type 2 diabetes susceptibility in European populations [2], with rs7903146 the better marker overall [7]. We tested the hypothesis that these TCF7L2 SNPs denoting type 2 diabetes risk also influence susceptibility to PCOS, using both case-control studies and analysis of androgen levels as a continuous trait relevant to PCOS.

\section{Methods}

UK case-control analysis All 369 UK cases had a definitive diagnosis of PCOS according to the Rotterdam diagnostic criteria [8]. Recruitment details have been described elsewhere [9]. All had a history of oligo- or amenorrhoea (inter-menstrual interval $>42$ days) and/or hyperandrogenism, the latter defined clinically (hirsutism or acne) and/or biochemically (serum total testosterone $>2.7 \mathrm{nmol} / \mathrm{l}$ ). In addition, all cases had polycystic ovarian (PCO) morphology confirmed on ultrasound [8]. All other potential endocrine and neoplastic causes of hyperandrogenaemia were excluded prior to recruitment. All were of European British/Irish origin and not pregnant at the time of study.

For comparison, controls from two population-based UK samples (all of European British/Irish origin) were used, as previously described [9]. The Human Random Control and 1958 British Birth Cohort control groups comprise 550 (270 women) and 2024 individuals (1010 women), respectively. Additional phenotypic data are not available for these controls. TCF $2 L 2$ genotype data for both control groups have previously been reported [4]. As there are no significant differences in genotype frequencies between the two UK control groups, our primary case-control analyses compared UK cases with the entire control group. In addition, since these are populationbased controls and there is no evidence of sex-specific differences in genotype frequency, our primary analysis included controls of both sexes, though we also present analyses restricted to female controls. Use of populationbased controls results in some loss of power compared with controls in whom disease has been excluded, but this is modest and easily overcome (as here) by increasing the control sample size.

Northern Finland Birth Cohort of 1966 In recognition of the spectrum of PCOS-related phenotypes within the general female population, we also analysed genotypes from 1623 singleton women from the Northern Finland Birth Cohort of 1966 (NFBC1966). This sample comprised 540 women with symptoms of PCOS (hirsutism and/or oligo- or amenorrhoea, defined as an inter-menstrual interval of $>35$ days), and 1083 controls (a random sample of women who reported no such symptoms), all examined at age 31 years [10]. A definitive diagnosis of PCOS [8] is not possible in this cohort; however, compared with the controls, these 'symptomatic cases' have an increased 
Table 1 Clinical characteristics of UK and Finnish NFBC1966 subjects

\begin{tabular}{llllll}
\hline & UK PCOS cases & UK HRC+ controls & UK 58BC controls & Finnish symptomatic cases & Finnish controls \\
\hline$n$ & $369^{\mathrm{a}}$ & 550 & 2024 & 540 & 1083 \\
Women (\%) & 100 & 49.0 & 49.9 & 100 & 100 \\
Age (years) & $32.0 \pm 7.1$ & Not known & Not available & $31^{\mathrm{b}}$ & $31^{\mathrm{b}}$ \\
BMI $\left(\mathrm{kg} / \mathrm{m}^{2}\right)$ & $26.9(20.7-34.9)$ & Not known & Not available & $24.4(20.3-29.4)$ & $23.8(20.0-28.3)$ \\
Waist to hip ratio & $0.79(0.72-0.88)$ & Not known & Not available & $0.82(0.74-0.90)$ & $0.81(0.73-0.88)$ \\
Testosterone (nmol/l) & $2.1^{\mathrm{c}}(1.4-3.3)$ & Not known & Not available & $2.0^{\mathrm{d}}(1.4-3.0)$ & $1.8^{\mathrm{d}}(1.2-2.8)$ \\
FAI & $5.5^{\mathrm{c}}(2.4-11.8)$ & Not known & Not available & $4.2^{\mathrm{d}}(2.1-7.3)$ & $3.1^{\mathrm{d}}(1.7-5.9)$ \\
Glucose $(\mathrm{mmol} / \mathrm{l})$ & $4.8^{\mathrm{c}, \mathrm{e}}(4.3-5.3)$ & Not known & Not available & $4.9^{\mathrm{d}, \mathrm{e}}(4.5-5.4)$ & $4.9^{\mathrm{d}, \mathrm{e}}(4.3-5.6)$ \\
\hline
\end{tabular}

Quantitative data are presented as geometric means (SD range) or means $\pm \mathrm{SD}$

HRC $+=$ Human Random Control; 58BC $=1958$ British Birth Cohort

${ }^{\mathrm{a}} \mathrm{UK}$ non-pregnant PCOS cases

${ }^{\mathrm{b}}$ All women in the NFBC1966 were sampled at the age of 31 years

${ }^{\mathrm{c}}$ Excluding those women on oral hypoglycaemic agents, metformin or hormonal therapy (oral contraception)

${ }^{\mathrm{d}}$ Excluding those women on oral hypoglycaemic agents, metformin, hormonal therapy (oral contraception or hormonal intra-uterine device) or those women pregnant at the time of examination

${ }^{\mathrm{e}}$ Fasting samples

prevalence of ultrasound-confirmed PCO morphology and biochemical features consistent with PCOS [10].

The clinical features of all case and control groups are shown in Table 1. Serum testosterone and sex hormonebinding globulin (SHBG) concentrations in the UK and Finnish groups were measured as previously described [9]. The free androgen index (FAI) was calculated as [total testosterone $\times 100] /$ SHBG. All clinical investigations were conducted in accordance with the principles of the Declaration of Helsinki as revised in 2000. All subjects provided fully informed written consent and the study was approved by the relevant ethics committees in the UK and Finland.
Genotyping In both the UK and Finnish samples, genotyping of rs7903146 and rs12255372 was performed by Kbiosciences (Hoddesdon, UK) using a fluorescence-based competitive allele-specific (KASPar) assay (details on request). Genotype success rates exceeded $95 \%$ in both the UK and Finnish samples. Based on 466 duplicate samples, the discrepancy error rate was estimated at $<0.2 \%$ for both variants. There was no departure from HardyWeinberg equilibrium $(p>0.05)$.

Statistical analyses and power calculations The CochranArmitage (additive) test was used for genotype-based case-

Table 2 Case-control association analyses for the relationship between variants at rs7903146 and PCOS in UK and Finnish groups

\begin{tabular}{|c|c|c|c|c|c|c|c|c|c|}
\hline \multirow[t]{2}{*}{ Genotype } & \multicolumn{3}{|l|}{ Cases } & & \multicolumn{4}{|l|}{ Controls } & \multirow{2}{*}{$\begin{array}{l}p \text { value vs } \\
\text { cases }\end{array}$} \\
\hline & $\mathrm{CC}$ & $\mathrm{CT}$ & $\mathrm{TT}$ & & & $\mathrm{CC}$ & $\mathrm{CT}$ & TT & \\
\hline \multirow[t]{6}{*}{ UK cases $(n=358)$} & \multirow[t]{6}{*}{$\begin{array}{l}177 \\
(49.4 \%)\end{array}$} & \multirow[t]{6}{*}{$\begin{array}{l}151 \\
(42.2 \%)\end{array}$} & \multirow[t]{6}{*}{$\begin{array}{l}30 \\
(8.4 \%)\end{array}$} & \multirow[t]{2}{*}{ UK HRC+ } & All $(n=510)$ & $\begin{array}{l}243 \\
(47.7 \%)\end{array}$ & $\begin{array}{l}217 \\
(42.5 \%)\end{array}$ & $\begin{array}{l}50 \\
(9.8 \%)\end{array}$ & $0.47^{\mathrm{a}}$ \\
\hline & & & & & $\begin{array}{l}\text { Females only } \\
(n=249)\end{array}$ & $\begin{array}{l}117 \\
(47.0 \%)\end{array}$ & $\begin{array}{l}108 \\
(43.4 \%)\end{array}$ & $\begin{array}{l}24 \\
(9.6 \%)\end{array}$ & $0.49^{\mathrm{a}}$ \\
\hline & & & & \multirow[t]{2}{*}{ UK 58BC } & All $(n=1966)$ & $\begin{array}{l}932 \\
(47.4 \%)\end{array}$ & $\begin{array}{l}867 \\
(44.1 \%)\end{array}$ & $\begin{array}{l}167 \\
(8.5 \%)\end{array}$ & $0.56^{\mathrm{a}}$ \\
\hline & & & & & $\begin{array}{l}\text { Females only } \\
\quad(n=994)\end{array}$ & $\begin{array}{l}483 \\
(48.6 \%)\end{array}$ & $\begin{array}{l}431 \\
(43.4 \%)\end{array}$ & $\begin{array}{l}80 \\
\quad(8.0 \%)\end{array}$ & $0.89^{\mathrm{a}}$ \\
\hline & & & & \multirow[t]{2}{*}{ Combined } & All $(n=2476)$ & $\begin{array}{l}1175 \\
(47.4 \%)\end{array}$ & $\begin{array}{l}1084 \\
(43.8 \%)\end{array}$ & $\begin{array}{l}217 \\
(8.8 \%)\end{array}$ & $0.51^{\mathrm{a}}$ \\
\hline & & & & & $\begin{array}{l}\text { Females only } \\
(n=1243)\end{array}$ & $\begin{array}{l}600 \\
(48.3 \%)\end{array}$ & $\begin{array}{l}539 \\
(43.4 \%)\end{array}$ & $\begin{array}{l}104 \\
(8.3 \%)\end{array}$ & $0.76^{\mathrm{a}}$ \\
\hline $\begin{array}{l}\text { Finnish symptomatic } \\
\text { cases }(n=476)\end{array}$ & $\begin{array}{l}301 \\
(63.2 \%)\end{array}$ & $\begin{array}{l}156 \\
(32.8 \%)\end{array}$ & $\begin{array}{l}19 \\
(4.0 \%)\end{array}$ & $\begin{array}{l}\text { Finnish } \\
\text { controls }\end{array}$ & $\begin{array}{l}\text { Females only } \\
\quad(n=936)\end{array}$ & $\begin{array}{l}620 \\
(66.2 \%)\end{array}$ & $\begin{array}{l}278 \\
(29.7 \%)\end{array}$ & $\begin{array}{l}38 \\
(4.1 \%)\end{array}$ & $0.36^{\mathrm{b}}$ \\
\hline
\end{tabular}

Data shown are genotype counts (percentages) (reduced numbers reflect genotype success rates outlined in methodology). The $p$ values represent Cochran-Armitage test results

HRC $+=$ Human Random Control; 58BC $=1958$ British Birth Cohort

${ }^{\mathrm{a}}$ Comparison with UK PCOS cases

${ }^{\mathrm{b}}$ Comparison with Finnish symptomatic cases 
control analyses (StatXact, version 6; Cytel, Cambridge, MA, USA). Quantitative trait analyses were conducted in SPSS (version 12.0; SPSS, Chicago, IL, USA), by one-way ANOVA following appropriate distributional transformations. Testosterone levels were optionally adjusted for BMI.

Power calculations were performed using Quanto, version 0.5.5 (log-additive model). In the UK and Finnish casecontrol analyses, sample sizes provided $85 \%$ and $70 \%$ power, respectively, to detect an allelic OR of 1.3 (rs7903146; $\alpha=$ 0.05 ). The continuous trait analyses had $80 \%$ power to detect a between-genotype trait difference exceeding 93, 95 and $56 \%$ of a SD in the UK, Finnish symptomatic cases and Finnish control groups, respectively ( $\alpha=0.05$ ).

In all samples studied, and in accordance with the previous literature, the correlation between genotypes at rs7903146 and rs12255372 was high $\left(r^{2}=0.79,0.71\right.$ and 0.68 in UK female controls, UK cases and the Finnish cohort, respectively). Given evidence favouring rs7903146 (or a close proxy thereof) as the aetiological variant, we present the data focusing on this SNP.

\section{Results}

The minor allele frequency for rs7903146 in UK PCOS cases was $29.5 \%$, similar to that seen in the UK control groups $(30.7 \%)$. Genotype frequency comparisons revealed no association with PCOS (Cochran-Armitage test, OR [per minor allele] $0.95,95 \%$ CI $0.80-1.12, p=0.51$; Table 2). Comparison with female controls alone was also non-significant (OR 0.97, 95\% CI 0.81-1.17, $p=0.76$ ). In the Finnish cohort, too, there was no association between rs7903146 and case-control status (Cochran-Armitage test, OR [per minor allele] $1.10,95 \%$ CI $0.90-1.34, p=0.36$; Table 2). Following the exclusion of women taking hormonal therapy, metformin or other oral hypoglycaemic agents, continuous trait analyses were conducted separately in UK cases $(n=168)$, Finnish symptomatic cases $(n=259)$ and Finnish controls $(n=822)$. Neither testosterone levels nor FAI showed a relationship with rs7903146 genotype in any of the groups (testosterone: UK cases, $p=0.99$; Finnish controls, $p=0.57$; Finnish symptomatic cases, $p=0.80$ ). Analyses of rs 12255372 generated similar results throughout (data not shown).

\section{Discussion}

This is the first study to test the hypothesis that type 2 diabetes-associated variants of TCF $7 L 2$ also affect susceptibility to PCOS. We found no evidence that these variants are associated with the development of PCOS or PCO- related phenotypes in well-powered case-control and quantitative trait analyses.

Common variants of TCF7L2 most likely influence type 2 diabetes susceptibility through impairment of insulin secretion [3]. The largest study to date, which genotyped TCF7L2 rs7903146 in 24,053 subjects including 4578 subjects from NFBC1966, has demonstrated a modest effect of genotype on the early insulin response to oral glucose [5]. Our findings therefore support the notion that, in contrast to type 2 diabetes, genetic variation influencing beta cell dysfunction is not a primary and essential determinant of PCOS pathogenesis. The present study was sufficiently powered to detect an effect size for PCOS similar in magnitude to that previously shown for type 2 diabetes susceptibility in UK populations (OR 1.36) [4]. Exclusion of a more modest effect than this would have required an appropriately larger sample.

To summarise, we provide evidence that common type 2 diabetes susceptibility variants of TCF7L2 have no association with the development of PCOS and no detectable influence on androgen levels in women. Our data provide the strongest indication yet that, despite apparent epidemiological and pathophysiological similarities, PCOS and type 2 diabetes feature qualitatively distinct genetic susceptibility effects. Our study is consistent with a model whereby genetic and environmental factors combine to influence insulin resistance in both type 2 diabetes and PCOS. Whilst variants that affect the capacity of the beta cell to respond to insulin insensitivity are likely to predominate in defining individual risk of type 2 diabetes, we hypothesise that factors involved in the ovarian response to insulin resistance are likely to be key to the development of PCOS.

Acknowledgements We thank the many patients, relatives, nurses, and physicians who contributed to the ascertainment of the clinical samples used in this study, and the UK Medical Research Council (grant G9700120) for funding this work. We acknowledge use of DNA from the British 1958 Birth Cohort collection, funded by the UK Medical Research Council grant G0000934 and Wellcome Trust grant (GR069224MA, 068545/Z/02). We also acknowledge the support of the Academy of Finland (M.-R. Järvelin) and NovoNordisk (Research Fellowship awarded to T. M. Barber).

Duality of interest The authors declare that there is no duality of interest associated with this manuscript.

\section{References}

1. Franks S (1995) Polycystic ovary syndrome. N Engl J Med 333:853-861

2. Grant SF, Thorleifsson G, Reynisdottir I et al (2006) Variant of transcription factor 7-like 2 (TCF7L2) gene confers risk of type 2 diabetes. Nat Genet 38:320-323

3. Zeggini E, McCarthy MI (2007) TCF7L2: the biggest story in diabetes genetics since HLA? Diabetologia 50:1-4 
4. Groves CJ, Zeggini E, Minton J et al (2006) Association analysis of 6,736 U.K. subjects provides replication and confirms TCF7L2 as a type 2 diabetes susceptibility gene with a substantial effect on individual risk. Diabetes 55:2640-2644

5. Freathy RM, Weedon MN, Bennett A et al (2007) Type 2 diabetes TCF7L2 risk genotypes alter birth weight: a study of 24,053 individuals. Am J Hum Genet 80:1150-1161

6. Holte J, Bergh T, Berne C, Berglund L, Lithell H (1994) Enhanced early insulin response to glucose in relation to insulin resistance in women with polycystic ovary syndrome and normal glucose tolerance. J Clin Endocrinol Metab 78:1052-1058

7. Helgason A, Palsson S, Thorleifsson G et al (2007) Refining the impact of TCF $7 L 2$ gene variants on type 2 diabetes and adaptive evolution. Nat Genet 39:218-225
8. The Rotterdam ESHRE/ASRM-sponsored PCOS consensus workshop group (2004) Revised 2003 consensus on diagnostic criteria and long-term health risks related to polycystic ovary syndrome (PCOS). Hum Reprod 19:41-47

9. Powell BL, Haddad L, Bennett A et al (2005) Analysis of multiple data sets reveals no association between the insulin gene variable number tandem repeat element and polycystic ovary syndrome or related traits. J Clin Endocrinol Metab 90:2988-2993

10. Taponen S, Martikainen H, Jarvelin MR et al (2004) Metabolic cardiovascular disease risk factors in women with self-reported symptoms of oligomenorrhea and/or hirsutism: Northern Finland Birth Cohort 1966 Study. J Clin Endocrinol Metab 89:21142118 